\title{
Short latency evoked potentials: new criteria for brain death?
}

\author{
E Facco, M Casartelli Liviero, M Munari, F Toffoletto, F Baratto, G P Giron
}

\begin{abstract}
The aim of this study was to evaluate whether the auditory brain stem responses (ABR) and short latency somatosensory potentials (SEP) from median nerve stimulation are effective tools in the confirmation of brain death. Thirty six brain dead patients were submitted to ABR and 24 to SEP in the same session. All waves of the $A B R$ were absent in $28(77.8$ per cent) patients, while only wave I was present in the others $(22 \cdot 2$ per cent). In SEP recordings the components later than P13 were absent in $17(70.8$ per cent) of cases; in the remaining seven patients (29.2 per cent) a N13/P13 dissociation (namely, retention of the cervical N13 and absence of the far-field P13) was found. The results suggest that SEP and ABR are reliable tools in the diagnosis of brain death and should be included in the criteria: they enable the functional status of two pathways in the brainstem to be checked, which cannot be explored by the clinical examination.
\end{abstract}

The diagnosis of brain death is an intriguing and complex problem involving a large field of knowledge and the subject has undergone a great evolution during the past two decades. Since the Harvard Criteria of brain death were published in $1968,{ }^{1}$ the very concept of brain death has progressively changed and the death of the brain stem has been increasingly identified as the essential criterion of brain death. ${ }^{2-6}$ However, some British physicians appear dissatisfied with the United Kingdom criteria, ${ }^{78}$ while in other countries, such as the United States and Italy, the EEG is either recommended or mandatory..$^{10}$

There appear to be three main causes for concern: a) the need for absolute certainty of diagnosis; b) the feasibility of assessing the death of the whole brainstem; ${ }^{7}$ c) the request for reliable instrumental investigations, to assure an "objective" confirmation of the diagnosis of brain death. ${ }^{11}$

None of the proposed investigations (such as EEG, angiography, cerebral blood flow and echo-doppler) allow a direct exploration of the brain stem. Furthermore, the EEG, which is the most widely used and often mandatory investigation, is far from being relevant. ${ }^{11}$

Among instrumental techniques, short latency evoked potentials are the only means capable of checking brain stem function. In this study we submitted 36 patients, brain dead according the the United Kingdom criteria, to auditory brainstem responses (ABRs) and to somatosensory evoked potentials (SEP) from the median nerve, to evaluate whether ABR and SEP may be accurate indicators of brain stem death and to help in answering the concerns outlined above.

\section{Subjects and methods}

Thirty six patients ranging between six and 65 years were submitted to ABR recording; in 24 the SEP from median nerve stimulation was recorded as well, at the same session. All the patients were clinically brain dead following structural brain damage; head injury was the cause of coma in 19 cases ( 52.8 per cent), subarachnoidal haemorrhage in 14 (38.8 per cent), brain tumours (after surgery) in two (5.6 per cent) and anoxia in one patient $(2 \cdot 8$ per cent). Patients with lesions or diseases capable of affecting or cancelling out the evoked responses (such as haemotympanum, fractures of the temporal bone or cervical vertebrae, or lesions of the brachial plexus) were discarded from this study.

SEP were recorded from each median nerve using a non cephalic reference; methods for $A B R$ and SEP recordings are described in detail elsewhere. ${ }^{1213}$ A BASIS EP equipment (ESAOTE Biomedica, Florence, Italy) was used for the ABR and SEP recordings.

\section{Results}

All waves of the ABR were absent in 28 patients $(77.8$ per cent), while in eight patients only wave I was present ( $22 \cdot 2$ per cent) (fig 1 ). Among the 28 patients, the ABR was monitored during the clinical course of coma in four cases, enabling us to follow the disappearance of the waves.

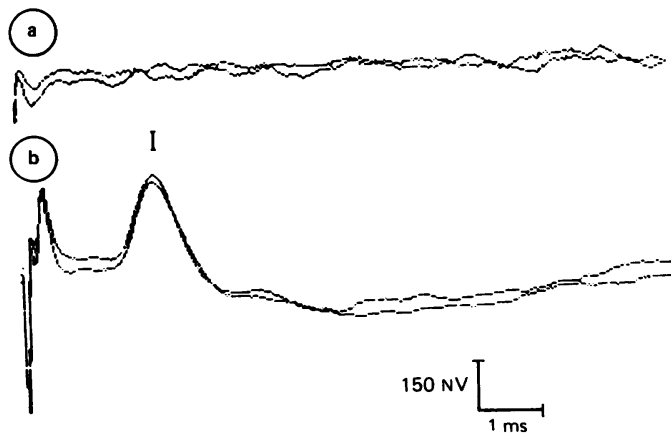

Figure $1 A B R$ in brain death: a) absent response; b) only the I wave is present. 
Figure 2 SEP from median nerve in brain death: a) only the N9$N 13$ and P9-P13 components are present; $\boldsymbol{b}$ ) dissociation N13/P13: the cervical N13 is still present, but the far-field scalp-recorded P13 is absent. $N C=$ non cephalic.

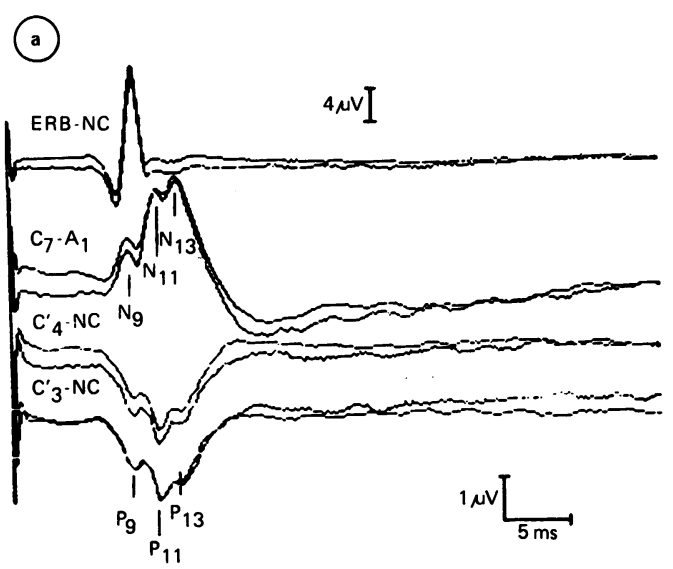

(b)

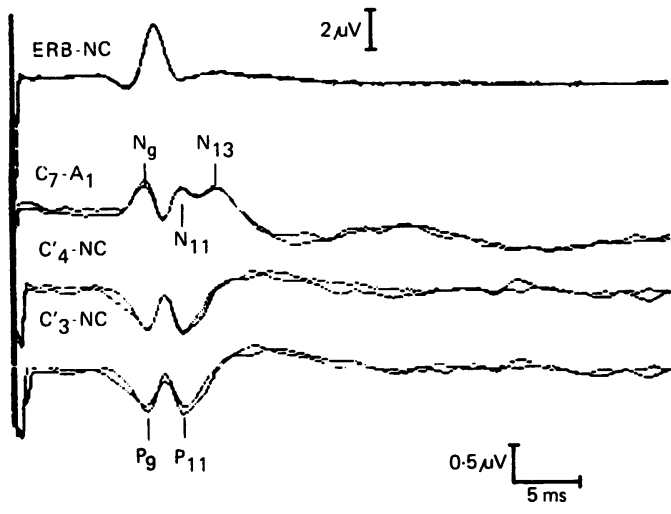

In SEP recordings the N9-N13 and P9-P13 waves were present in 17 out of 24 patients ( 70.8 per cent), but later components were absent. In the remaining seven patients $\mathbf{2 9} \cdot 2$ per cent) a dissociation between the cervical N13 and the far-field scalp-recorded P13 (namely, retained N13 and absent P13) was found (fig 2).

\section{Discussion}

$A B R$ and SEP allow a non-invasive exploration of auditory and somatosensory pathways in the brain stem; moreover they are not abolished in reversible coma due to metabolic or toxic causes, sedative or anaesthetic administration, not even in barbiturate coma. These features make them potentially useful in the diagnosis of brain death.

The absence of all waves of the ABR in about 2/3-3/4 of brain death patients has been reported in the literature; ${ }^{12}{ }^{14-16}$ this picture, which is due to cochlear ischaemia from arrest of the cerebral circulation, ${ }^{17}$ is the reason for the limited value assigned to the $A B R$ in proving brain death. Conversely, the SEP is able to assess the absence of brain activity in 60-100 per cent of cases, ${ }^{12}{ }^{18-20}$ but in most studies a frontal reference was used, which does not allow the recording of far-field potentials $(\mathrm{P} 13,14$ and $\mathrm{N} 18)$ generated in the brain stem: consequently, the use of frontal reference cannot discriminate whether the absence of N20 depends upon hemispheric or brain stem damage.

The aim of this study was to evaluate the role of ABR and SEP in the diagnosis of brain death. As in our previous report, ${ }^{2}$ all waves of the ABR were absent in some $3 / 4$ of cases, while no components beyond wave I were recordable in the remaining patients; the serial monitoring peformed in four cases during the clinical course of coma gave evidence that the progressive disappearance of the waves was brain death-related. The diagnostic value of ABR monitoring in pre-terminal states has been recently emphasised by Garcia-Larrea $e t$ $a l .^{20}$ Our data clash with those reported by Goldie et $a l^{15}$ while Starr ${ }^{14}$ found a slightly lower rate of absent ABR (59 per cent); the difference may reflect sample variations and/ or differences in test-timing in relation to the onset of brain death state. In this series no false positives were found.

Where SEP is concerned, there is now evidence that the cervical N13 arises from the cervical spinal cord, while the scalp-recorded far-field P13 is generated just above the foramen magnum, namely in the nucleus cuneatus or medial lemniscus: $:^{21}$ the presence of P13 in some 70 per cent of cases indicated the arrest of conduction in the lower brain stem, whereas the dissociation $\mathrm{N} 13 / \mathrm{P} 13$ was able to show the absence of activity above the foramen magnum in the remaining patients, strictly in accordance with the concept of brain stem death. These data agree with a previous neuropathological study, showing an intact cervico-medullary junction in 57 per cent of brain dead patients. ${ }^{22}$ Furthermore, they show that in most clinically brain dead patients the most caudal part of the brain stem is not yet dead: this may contradict the theoretical concept of brain stem death, although it does not necessarily appear to contradict the actual death of the "brain stem as a functional unit". Whatever the conceptual aspect, these data suggest a great sensitivity of SEP in confirming brain stem death.

In conclusion, our results suggest that: a) The ABR can only confirm the diagnosis of brain death in a minority of cases, unless serial monitoring is performed in pre-terminal states (to check the progressive disappearance of waves). Conversely, the SEP is able to confirm brain death in most, if not all, cases: the disappearance of all waves beyond the P13 components in 100 per cent of cases in our series, clearly showed the arrest of conduction near the foramen magnum and gave evidence of no residual sentience during organ donation. b) The close correlation between clinical signs of brain death and ABR and SEP data in our series, as well as in the literature, ${ }^{1214} 151618-20$ confirms the effectiveness of clinical diagnosis of brainstem death; however the previous report of sporadic false positives ${ }^{12} 18$ suggests that ABR and SEP might improve the safety of diagnosis. As ABR and SEP are not seriously affected by sedatives and anaesthetics nor by metabolic disorders, they may play a double role in the diagnosis of brain death: they can both facilitate the exclusions and confirm the clinical diagnosis. The ABR, although less reliable than SEP in proving brain death, keeps all its value in its exclusion. Moreover, both 
ABR and SEP allow the assessment of brain stem function even when brain stem reflexes are not reliable because of facial trauma. c) ABR and SEP are able to provide an "objective" confirmation of the clinical diagnosis of brain death, the need for which has been already discussed. ${ }^{11}$ d) Finally, ABR and SEP, like any other sign, have limits and pitfalls (that is, factors capable of affecting the evoked responses, but unrelated to brain death), which must be carefully excluded.

Although the United Kingdom criteria for brain death give a reasonable certainty of diagnosis, we believe that ABR and SEP should be included in the criteria. As the concept of brain stem death implies the assessment of death of the whole brain stem (or, of all explorable pathways in the brain stem), ABR and SEP should be regularly recorded: for they provide a check on the functional status of two pathways which cannot be explored by the clinical examination.

1 Harvard Medical School ad Hoc Committee to examine the definition of brain death A definition of irreversible coma. definition of brain death. A

2 Pallis C. ABC of brain stem death. Reappraising death. $\mathrm{Br}$ Med $J$ 1982;285:1409-12.

3 Pallis C. ABC of brain stem death. From brain death to brain stem death. $\operatorname{Br} M e d J 1982 ; 285: 1487-90$

4 Pallis C. ABC of brain stem death. Diagnosis of brain stem death-I. Br Med J 1982;285:1558-60.

5 Pallis C. ABC of brain stem death. Diagnosis of brain stem death-II. Br Med J 1982;285:1641-4.

6 Pallis C. ABC of brain stem death. Pitfalls and safeguards. $\mathrm{Br}$ Med J 1982;285:1720-2.

7 Hill DJ, Evans DW, Campbell RC. Brain stem death. $\mathrm{Br}$ Med J 1984:289:1620.
8 Moore EJH. British criteria for brain death: views of career grade doctors in Scotland. $\mathrm{Br} \mathrm{Med} J$ 1984;288:565-6.

9 Disciplina dei prelievi di parti di cadavere a scopo di trapianto terapeutico e norme sul prelievo dell'ipofisi da cadavere a scopo di produzione di estratti per uso terapeutico. Gazzetta Ufficiale della Repubblica Italiana terapeutico. Gazzetc

10 Report of the Medical Consultants on the diagnosis of brain death to the President's Commission on the study of ethical problems in medicine and biomedical and behavioural research: Guidelines for the determination of death. $J A M A 1981 ; 246: 2184-6$.

11 Pallis $C$. ABC of brain stem death. The arguments about the EEG. Br Med J 1983;286:284-7.

12 Facco E, Caputo P, Casartelli Liviero M. et al. Auditory and somatosensory evoked potentials in brain-dead patients. Rivista di Neurologia 1988;58:140-5.

13 Facco E, Munari M, Casartelli Liviero $M$, et al. Serial recordings of auditory brainstem responses in severe head injury: relationship between test timing and prognostic injury: relationship between test timing and

14 Starr A. Auditory brainstem responses in brain death. Brain 1976;99:543-54.

15 Goldie WD, Chiappa KH, Young RR, Brooks EB. Brainstem auditory and short latency somatosensory evoked responses in brain death. Neurology 1981;31:248-56.

16 Steinhart CM, Weiss IP. Use of brainstem auditory evoked potentials in pediatric brain death. Crit Care Med 1985;13:560-2.

17 Chiappa KH. Evoked Potentials in Clinical Medicine. Raven Press: New York, 1983.

18 Anziska BJ, Cracco RQ. Short latency somatosensory evoked potentials in brain dead patients. Arch Neurol 1980;37:222-5.

19 Belsh JM, Chokroverty S. Short-latency somatosensory evoked potentials in brain-dead patients. Electroenceph Clin Neurophysiol 1987;68:75-8.

20 Garcia-Larrea L, Bertrand O, Artru F, Pernier J, Mauguiere F. Brainstem monitoring in coma II: dynamic interpretation of preterminal BAEP changes observed until brain death in deeply comatose patients. Electroenceph Clin Neurophysiol 1987;68:446-57.

21 Mauguiere F, Ibanez V, Deiber MP, Garcia-Larrea L. Noncephalic reference recording and spatial mapping of short-latency SEPs to upper limb stimulation: normal responses and abnormal patterns in patients with nondemyelinating lesions of the CNS. In: Barber C, Blum T, eds. Evoked Potentials III. Stoneham: Butterworths, 1987,40-55.

22 Walker AE, Diamond EL, Moseley J. The neuropathological fidings in irreversible coma. $J$ Neuropathol Exp Neurol 1975;34:295-323. 